\title{
Antibacterial activity of ethanolic extracts obtained from roots and stems of Chelidonium majus L. against Enterococcus faecalis strains
}

\author{
Nataniel Stefanowski, Halyna Tkachenko*, Natalia Kurhaluk \\ Institute of Biology and Earth Sciences, Pomeranian University in Słupsk, Poland \\ ORCID \\ Halyna Tkachenko: https://orcid.org/0000-0003-3951-9005 \\ Natalia Kurhaluk: https://orcid.org/0000-0002-4669-1092
}

Article Details:

Received: $\quad$ 2021-08-18

Accepted: $\quad$ 2021-09-04

Available online: 2021-11-30

DOI: https://doi.org/10.15414/ainhlq.2021.0028

\begin{abstract}
The present study is in vitro research aimed to evaluate the antimicrobial activity of the ethanolic extracts derived from roots and stems of Chelidonium majus L. against two Enterococcus faecalis strains to assess the possible use of this plant in preventing infections caused by this pathogen. Plant materials were harvested from natural habitats on the territory of the Kartuzy district in the Pomeranian province (northern part of Poland). The collected roots and stems were brought into the laboratory for antimicrobial studies. Freshly washed samples were weighed, crushed, and homogenized in $96 \%$ ethanol (in proportion $1: 19, \mathrm{w} / \mathrm{w}$ ) at room temperature. The extracts were then filtered and investigated for their antimicrobial activity. The Enterococcus faecalis (Andrewes and Horder) Schleifer and KilpperBalz (ATCC $® 51299^{\mathrm{TM}}$ ) and linezolid-resistant Enterococcus faecalis strain locally isolated were used in the current study. The antimicrobial susceptibility testing was done on Muller-Hinton agar by Kirby-Bauer disk diffusion susceptibility test protocol. The results of the current study showed that $C$. majus possess weak antimicrobial properties against the tested Enterococcus faecalis strains. The ethanolic extracts derived from roots of $C$. majus collected from rural areas exhibited the maximum antimicrobial activity against linezolid-resistant $E$. faecalis strain (the mean of inhibition zone diameters was $8.85 \pm 0.42 \mathrm{~mm}$ ) compared to the control samples $(7.1 \pm 0.91 \mathrm{~mm})$. Stem extracts derived from $C$. majus collected from rural areas showed similar properties against the Enterococcus faecalis (Andrewes and Horder) Schleifer and Kilpper-Balz $\left(\right.$ ATCC $\left.® 51299^{\mathrm{TM}}\right)$ strain $(8.77 \pm 1.21 \mathrm{~mm})$ compared to the control samples. Root extracts derived from C. majus collected from urban and rural areas exhibited weak antibacterial ability against linezolid-resistant $E$. faecalis strains (6.46 $\pm 0.32 \mathrm{~mm}$ and $7.78 \pm 0.34 \mathrm{~mm}$, respectively), as well as weak antibacterial ability against E. faecalis ATCC $® 51299^{\mathrm{TM}}$ strains $(7.9 \pm 1.08 \mathrm{~mm}$ and $7.97 \pm 0.85 \mathrm{~mm}$, respectively) compared to the control sample $(7.1 \pm 0.99 \mathrm{~mm})$. The results of this study can induce to provide a new perspective for the use of various Papaveraceae families as medicinal plants to improve the antibacterial responses using other strains. Identification of precise molecular mechanisms responsible for inhibition of bacterial growth by these extracts requires further research.
\end{abstract}

Keywords: Chelidonium majus, linezolid-resistant Enterococcus faecalis strain, Enterococcus faecalis (Andrewes and Horder) Schleifer and Kilpper-Balz (ATCC®51299 ${ }^{\mathrm{TM}}$ ), antibacterial efficacy, disc diffusion technique, ethanolic extracts

\footnotetext{
*Corresponding Author: Halyna Tkachenko, Institute of Biology and Earth Sciences, Pomeranian University in Słupsk, Arciszewski Str. 22b, 76-200 Słupsk, Poland

$\triangle$ tkachenko@apsl.edu.pl
} 


\section{Introduction}

Enterococcus faecalis is a Gram-positive bacterium that commonly inhabits the gastrointestinal tract of mammals (Huycke et al., 1998; Brewer et al., 2020). Enterococcal species are core constituents of the intestinal flora of many animal species ranging from humans to flies (Macovei et al., 2006; McBride et al., 2007). When they enter a wound, bloodstream, or urinary tract, however, E. faecalis cells can cause serious infections. In immunocompromised individuals, however, it can cause a variety of complications, including surgical wound and urinary infections, endocarditis, and bacteremia (Macovei et al., 2006; Fisher and Phillips, 2009; García-Solache, 2019). E. faecalis is also resilient when exposed to a variety of stressors, allowing it to survive outside the body for extended periods of time, which likely increases transfer to patients in a hospital setting (Shepard and Gilmore, 2002). The ability of E. faecalis isolates to cause serious infections has been linked to the intrinsic ruggedness of the bacterium, which allows the organism to persist in the hospital environment and survive many host defenses, compounded by the acquisition of a variety of variable virulence traits by horizontal transfer from other organisms (Bonten et al., 1993; Shepard and Gilmore, 2002). Further, E. faecalis is resistant to a variety of antibiotics, complicating treatment strategies. Bacteria can survive antibiotic treatment through both resistance and tolerance (Murray, 1990). Resistance is defined as the inherited ability of microorganisms to grow in the presence of an antibiotic even at high concentrations, as indicated by high MIC values. The threat of E. faecalis to human health is further emphasized by its intrinsic low-level susceptibility to most of the available antibiotics, making treatment challenging (Murray, 1990; Bonten et al., 1993; Fisher and Phillips, 2009).

Many medical plants, for example, the Papaveraceae family, possessed significant antibacterial and antifungal activities against bacteria and other pathogens (Gerenčer et al., 2016). Chelidonium majus L., also known as greater celandine, is a plant of the family Papaveraceae, which grows wild in part of Asia, Central and Southern Europe, in the Azores and North America (Pantano et al., 2017). Chelidonium majus is a short-lived hemicryptophyte. It has up to $1 \mathrm{~m}$ high stem, branched and sparsely pubescent. The alternately placed leaves are light bluish at the bottom and green at the top. The basal leaves are long-petioled, with the obovate in contour, pinnatisect leaflets with 5-7 lobed segments. From April to October, the plant produces umbellate inflorescences with 2-6 flowers, which have 4 bright yellow petals and two whitish, early dropping sepals. The phytochemical and pharmacological properties, including the antibacterial activity of $C$. majus, have been reviewed, which is of great interest for its use in Chinese, Asian, and European herbal medicines The antimicrobial activity of C. majus is attributed mostly to the alkaloids and flavonoids (Zuo et al., 2008; Zielińska et al., 2018). The plant contains, first of all, alkaloids: benzylisoquinolic compounds (0.01-1.0 \%), such as sanguinarine, chelidonine, chelerythrine, protoberberine, and berberine. According to many researchers, the antibacterial effect ascribed to $C$. majus herb depends first of all on quaternary ammonium groups of isoquinoline alkaloids (Colombo and Bosisio, 1995; Lenfeld et al., 2007; Zuo et al., 2008; Zielińska et al., 2018).

Considering the points previous results obtained in our laboratory, the current study aimed to find out in vitro the possible antimicrobial activity of the ethanolic extracts derived from roots and stems of C. majus collected in urban and rural agglomerations of Kartuzy district in the Pomeranian province (northern part of Poland) against two Enterococcus faecalis strains, i.e. Enterococcus faecalis (Andrewes and Horder) Schleifer and Kilpper-Balz (ATCC $® 51299^{\mathrm{TM}}$ ) and linezolidresistant Enterococcus faecalis strain locally isolated.

\section{Material and methodology}

\section{Collection of plant material}

Plants of Chelidonium majus (Figure 1B) were harvested from natural habitats on the territory of the Kartuzy district $\left(54^{\circ} 20^{\prime} \mathrm{N} 18^{\circ} 12^{\prime} \mathrm{E}\right)$ in the Pomeranian province (northern part of Poland) (Figure 1A). Kartuzy is located about 32 kilometers (20 miles) west of Gdańsk and $35 \mathrm{~km}$ (22 miles) south-east of the town of Lębork on a plateau at an altitude of approximately 200 meters (656 feet) above sea level on average. The plateau, which is divided by the Radaune lake, comprises the highest parts of the Baltic Sea Plate (http://www.kartuzy.pl/). Plants were collected from urban $(n=5)$ and rural agglomerations $(n=15)$ on the territory of the Kartuzy district.

\section{Preparation of plant extracts}

The collected roots and stems of C. majus were brought into the laboratory for antimicrobial studies. Freshly washed samples were weighed, crushed, and homogenized in $96 \%$ ethanol (in proportion 1 : 19, $\mathrm{w} / \mathrm{w}$ ) at room temperature. Then the extracts were filtered and investigated for their antimicrobial activity. 

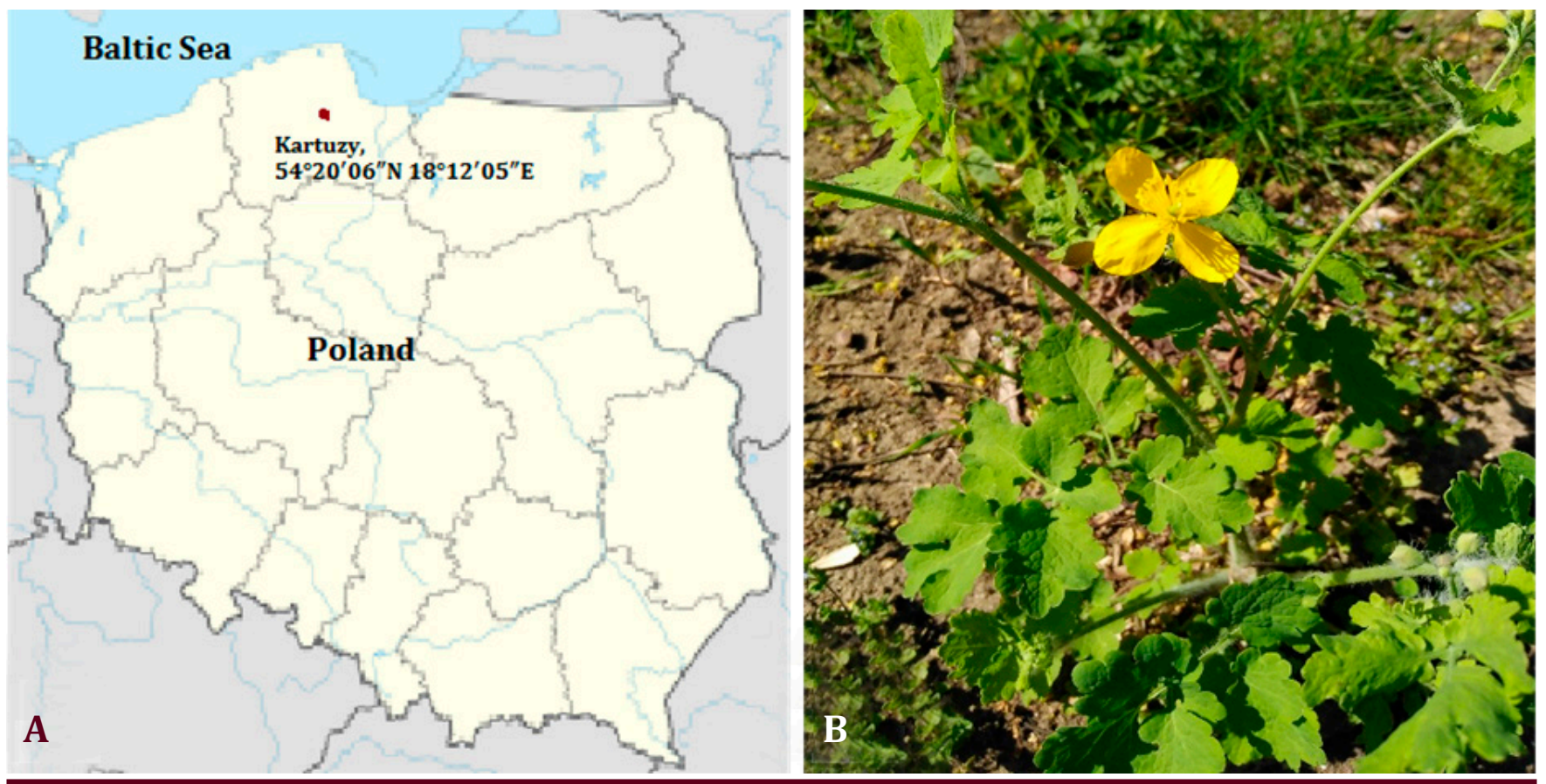

Figure 1 Location of Kartuzy in the map of Poland (A), where the Chelidonium majus L. (B) was collected Photo by Nataniel Stefanowski

\section{The disk diffusion method for evaluation of antibacterial activity of plant extracts}

The Enterococcus faecalis (Andrewes and Horder) Schleifer and Kilpper-Balz (ATCC $\left(51299^{\mathrm{TM}}\right.$ ) and linezolid-resistant Enterococcus faecalis strain locally isolated were used in the current study. Strains tested were plated on TSA medium (Tryptone Soy Agar) and incubated for $24 \mathrm{~h}$ at $37^{\circ} \mathrm{C}$. Then the suspension of microorganisms was suspended in sterile PBS and the turbidity adjusted equivalent to that of a 0.5 McFarland standard. The antimicrobial susceptibility testing was done on Muller-Hinton agar by Kirby-Bauer disk diffusion susceptibility test protocol (Bauer et al., 1966). Muller-Hinton agar plates were inoculated with $200 \mu \mathrm{l}$ of standardized inoculum $\left(10^{8} \mathrm{CFU} / \mathrm{mL}\right)$ of the bacterium and spread with sterile swabs.

Sterile filter paper discs impregnated by extracts were applied over each of the culture plates, $15 \mathrm{~min}$ after bacteria suspension was placed. A negative control disc impregnated by sterile $96 \%$ ethanol was used in each experiment. After culturing bacteria on MuellerHinton agar, the disks were placed on the same plates and incubated for $24 \mathrm{~h}$ at $37{ }^{\circ} \mathrm{C}$. The assessment of antimicrobial activity was based on the measurement of the diameter of the inhibition zone formed around the disks. The diameters of the inhibition zones were measured in millimeters and compared with those of the control and standard susceptibility disks. The activity was evidenced by the presence of a zone of inhibition surrounding the well (CLSI, 2014). The results of the disk diffusion test are "qualitative", in that a category of susceptibility (i.e., susceptible, intermediate, or resistant) is derived from the test rather than a MIC (Jorgensen and Ferraro, 2009).

\section{Statistical analysis}

Zone diameters were determined and averaged. Statistical analysis of the data obtained was performed by employing the arithmetic means \pm S.E.M. All variables were randomized according to the antibacterial activity of tested extracts. All statistical calculation was performed on separate data from each extract. The data were analyzed using one-way analysis of variance (ANOVA) using Statistica software, version 13.3 (StatSoft, Poland) (Zar, 1999). The following zone diameter criteria were used to assign susceptibility or resistance of bacteria to the phytochemicals tested: Susceptible (S) $\geq 15 \mathrm{~mm}$, Intermediate (I) $=10-15 \mathrm{~mm}$, and Resistant (R) $\leq 10 \mathrm{~mm}$ (Okoth et al., 2013).

\section{Results and discussion}

Our study aimed to examine the antibacterial properties of $C$. majus roots and stems against two Enterococcus faecalis strains: Enterococcus faecalis (Andrewes and Horder) Schleifer and Kilpper-Balz (ATCC $® 51299^{\mathrm{Tm}}$ ) and linezolid-resistant Enterococcus faecalis strain locally isolated. The extracts of stems and roots of C. majus collected from rural and urban agglomerations 


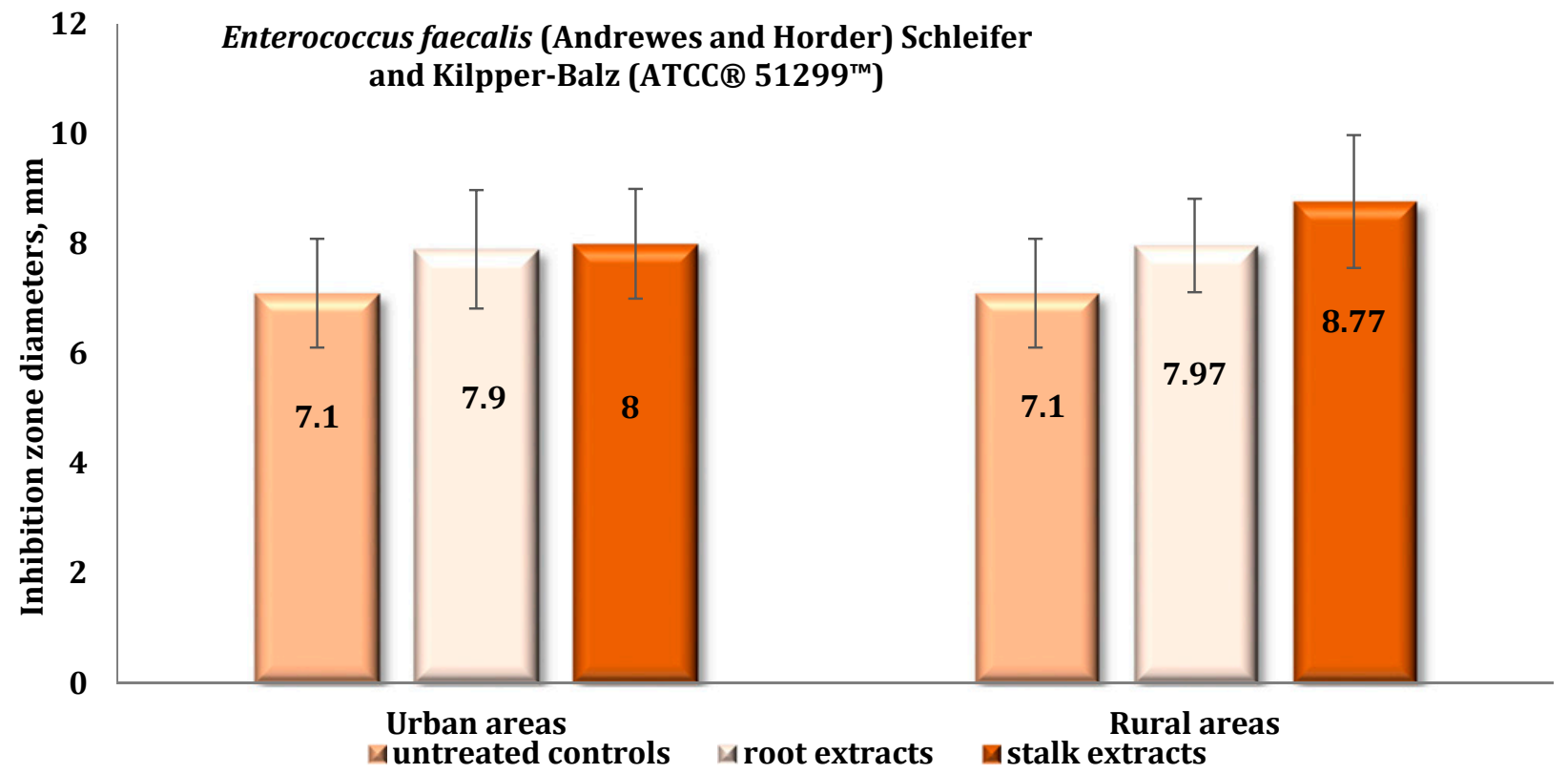

Figure 2 Zones of growth inhibitions of Enterococcus faecalis (Andrewes and Horder) Schleifer and Kilpper-Balz (ATCC $® 51299^{\mathrm{TM}}$ ) strain induced by the extracts obtained from stems and roots of Chelidonium majus L. collected from the rural and urban agglomerations in millimeter $(M \pm m, n=8)$

did not show antimicrobial activity against the tested strains. The results of antibacterial activity screening are given in Figure 2-5. The data on diameters of zone inhibition of bacterial growth of plant extracts against the Enterococcus faecalis (Andrewes and Horder) Schleifer and Kilpper-Balz (ATCC $® 51299^{\mathrm{TM}}$ ) strain is demonstrated in Figures 2 and 3. Figures 4 and 5 show data on the diameters of the zones of bacterial inhibition in plant extracts against linezolid-resistant Enterococcus faecalis strain locally isolated.
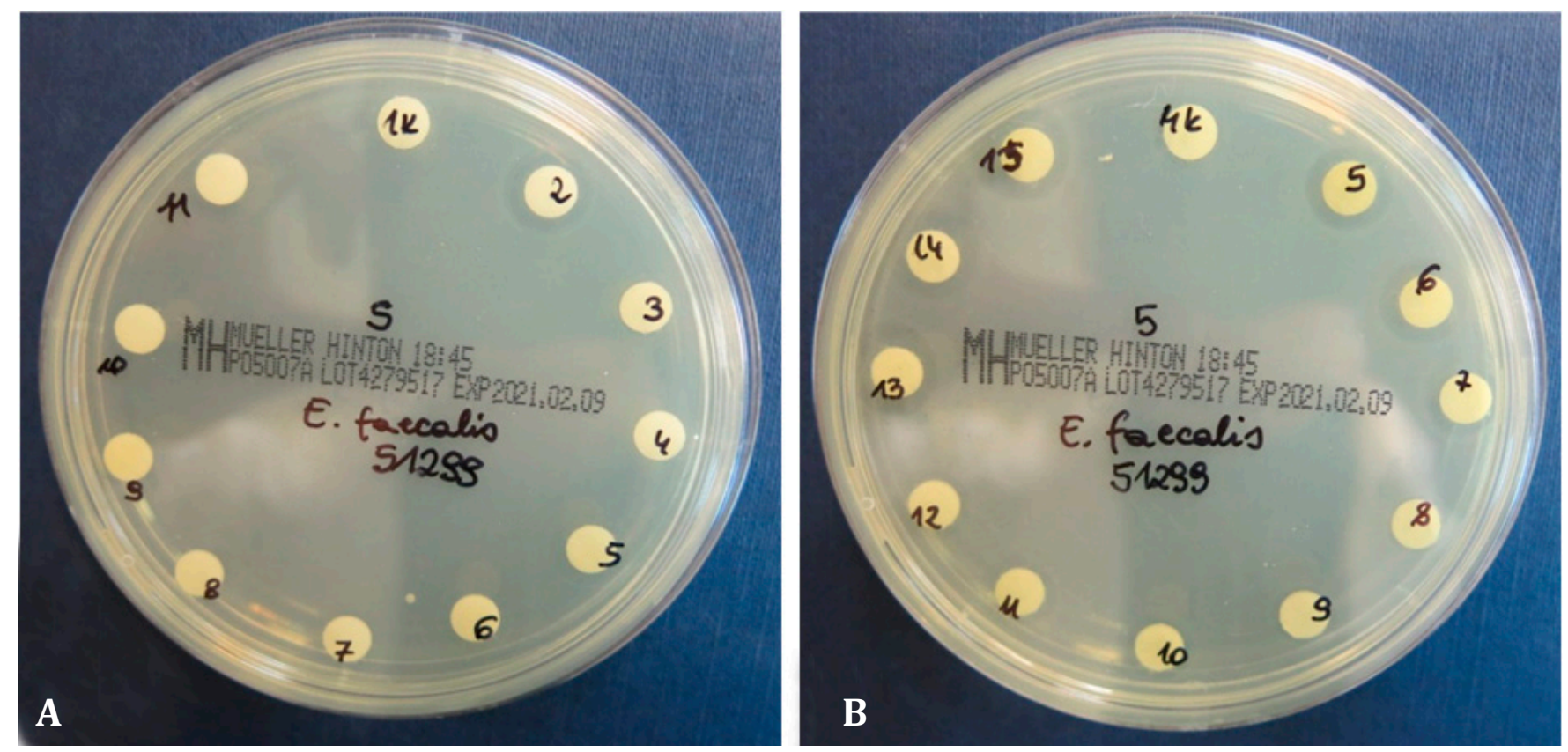

Figure 3 Example of plates in a disc diffusion assay showing the halos in the bacterial growth resulting from the antibacterial activity of extracts derived from roots (A) and stems of Chelidonium majus L. (B) collected from the rural and urban agglomerations against Enterococcus faecalis (Andrewes and Horder) Schleifer and Kilpper-Balz (ATCC® $51299^{\text {тM }}$ ) strain 


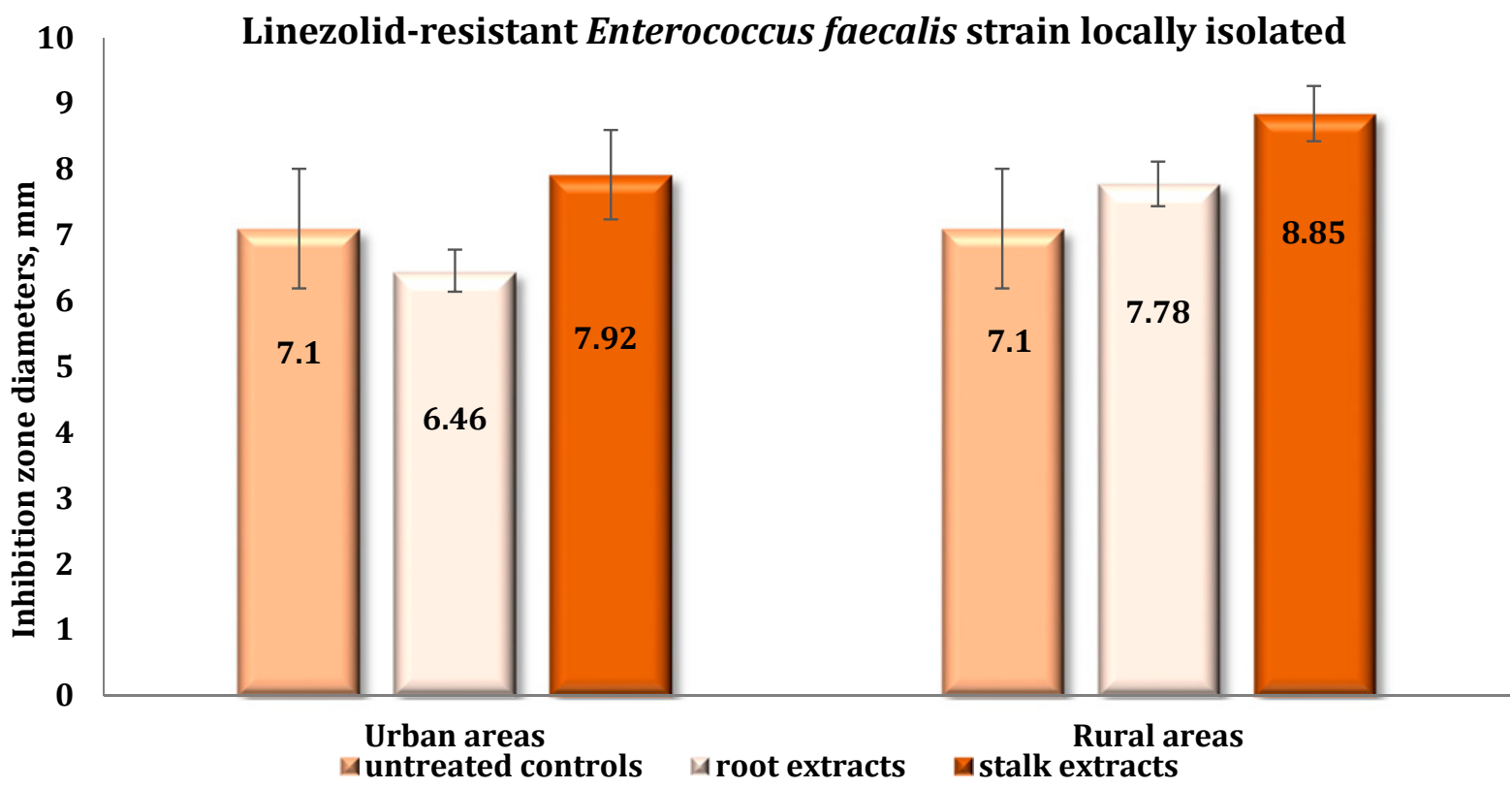

Figure 4 Zones of growth inhibitions of linezolid-resistant Enterococcus faecalis strain locally isolated induced by the extracts obtained from stems and roots of Chelidonium majus L. collected from the rural and urban agglomerations in millimeter $(\mathrm{M} \pm \mathrm{m}, \mathrm{n}=8)$

Our results evaluating the antibacterial properties against Enterococcus faecalis (Andrewes and Horder) Schleifer and Kilpper-Balz (ATCC $囚 51299^{\mathrm{TM}}$ ) strain are as follows (Figure 2). The ethanolic extract of C. majus derived from roots collected from rural agglomerations exhibited the maximum antimicrobial activity against $E$. faecalis (the mean of inhibition zone diameters was $8.77 \pm 1.21 \mathrm{~mm}$ ) compared to the control samples $(7.1 \pm 0.99 \mathrm{~mm})$. There was a $25 \%$ ( $p>0.05$ ) increase in the zone of inhibition compared to the control samples. Stem extracts of CM collected from urban areas also exhibited antibacterial ability against E. faecalis strain $(7.9 \pm 1.08 \mathrm{~mm})$ compared to the control samples $(7.1 \pm 0.99 \mathrm{~mm})$. There was
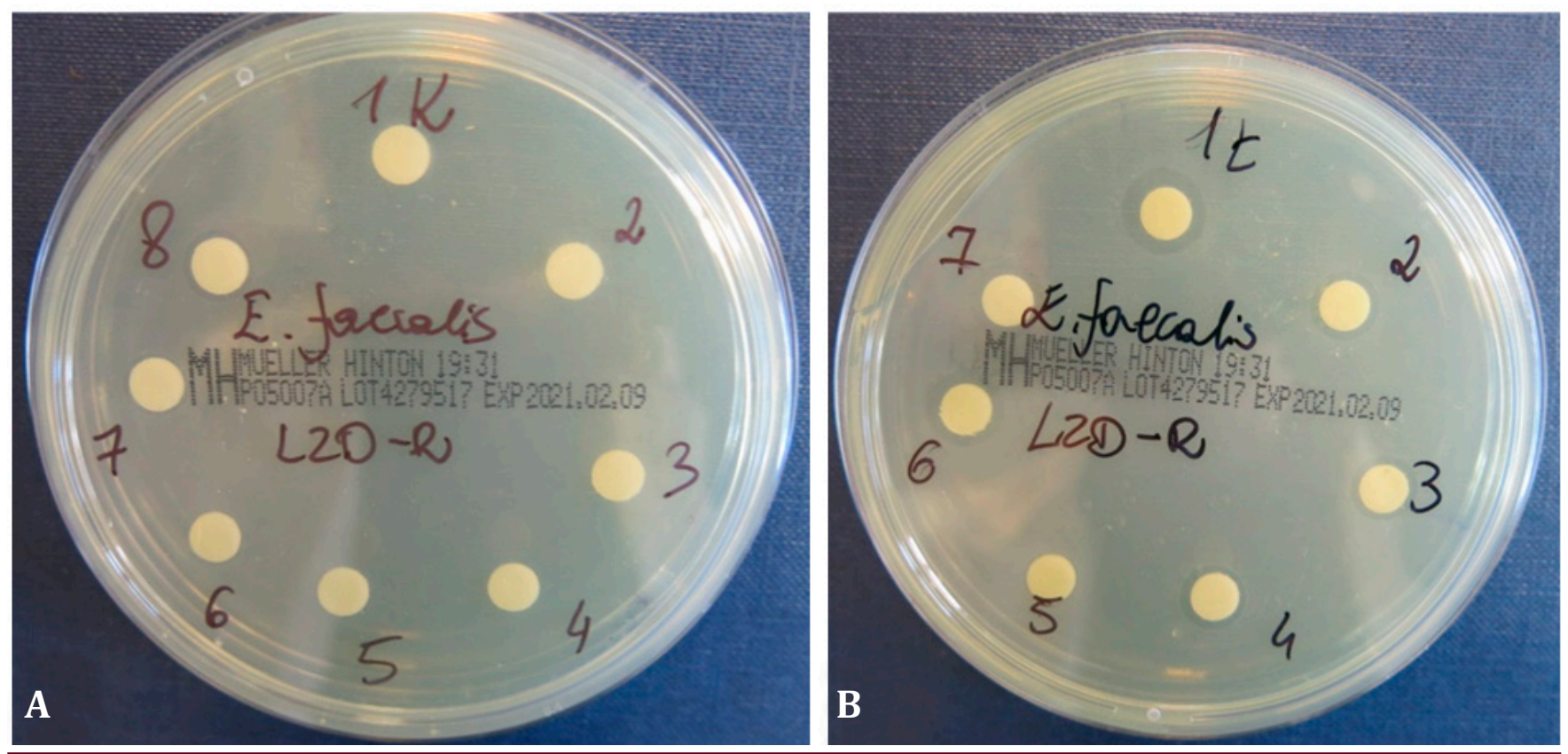

Figure 5 Example of plates in a disc diffusion assay showing the halos in the bacterial growth resulting from the antibacterial activity of extracts derived from roots (A) and stems of Chelidonium majus L. (B) collected from the rural and urban agglomerations against linezolid-resistant Enterococcus faecalis strain locally isolated 
a non-significant increase in the zone of inhibition by $11 \%$ ( $p>0.05$ ) compared to the control samples. Stem extracts also showed antibacterial properties against the E. faecalis strain, but a larger diameter of the zone of inhibition was observed in stem extracts of $C$. majus collected from rural areas $(7.97 \pm 0.85 \mathrm{~mm})$ compared to the control samples $(7.1 \pm 0.99 \mathrm{~mm})$. E. faecalis strain was also susceptible to the stem extracts of $C$. majus collected from urban agglomerations $(7.9 \pm 1.08 \mathrm{~mm})$ (Figures 2, 3).

Similar results were obtained after analysis of the zones of growth inhibition against linezolid-resistant Enterococcus faecalis strain locally isolated. The present study showed that the highest zone of growth inhibition against $E$. faecalis strain was exhibited by ethanolic stem extracts of $C$. majus collected from rural agglomerations as compared to the control samples (inhibition zone diameter were ranged from 7.1 to $9.35 \mathrm{~mm}, 8.85 \pm 0.42 \mathrm{~mm}$ ) (Figure 4). Moreover, it has been observed that ethanolic extracts derived from stems of $C$. majus collected from urban areas also revealed similar activity $(7.0-8.75 \mathrm{~mm}$ as the diameters of inhibition zone, $7.92 \pm 0.68 \mathrm{~mm}$ ) compared to the control samples (Figures 4 and 5).

The extracts derived from roots of $C$. majus collected in urban agglomerations have shown weak activity against the E. faecalis strain (Figure 4). The mean diameters of inhibition zones were $(6.46 \pm 0.32 \mathrm{~mm})$ compared to the control samples $(7.1 \pm 0.91 \mathrm{~mm})$. The extracts taken from the C. majus collected from the rural agglomerations showed no significant changes compared to the control samples. The above-presented results confirm the weak antibacterial activity of C. majus extracts against the tested E. faecalis strains (Figure 5).

In the present study, the antimicrobial activity of plant extracts was investigated by the agar disc diffusion method. In the current study, extracts from roots and stems of $C$. majus collected from rural and urban agglomerations were not effective against the tested bacteria due to the observed zone of growth inhibition. In our previous studies (Stefanowski et al., 2021a, b, c), we obtained different results against the tested strains. Regarding a strain of Staphylococcus aureus subsp. aureus Rosenbach (ATCC $® 29213^{\mathrm{TM}}$ ), we demonstrated high antimicrobial activity of both stem and root extracts of $C$. majus collected from urban areas by measuring zones of growth inhibition (for root extracts $16.9 \mathrm{~mm}$, for stems extracts $13.6 \mathrm{~mm}$ ) compared to the control samples $(8.8 \mathrm{~mm})$. By investigating the antibacterial activity of C. majus extracts against Staphylococcus aureus NCTC 12493 strain, we demonstrated that stem extracts of $C$. majus collected from both urban and rural agglomerations exhibited high antibacterial activity (15.3 and $13.1 \mathrm{~mm}$, respectively) compared to the control samples $(9.1 \mathrm{~mm})$, and increasing of the zones of growth inhibition was statistically significant. Our subsequent studies against Enterococcus faecalis (Andrewes and Horder) Schleifer and Kilpper-Balz (ATCC $® 51299^{\mathrm{Tm}}$ ), Escherichia coli (Migula) Castellani and Chalmers (ATCC ${ }^{2} 25922^{\mathrm{TM}}$ ), Escherichia coli (Migula) Castellani and Chalmers (ATCC $® 35218^{\mathrm{TM}}$ ) strains showed that stem extracts of $C$. majus exerted significant antibacterial effects assessing the zone of growth inhibition (Stefanowski et al., 2021a, b, c).

Our results are not similar to results obtained by other researchers. According to Kokoška et al. (2002), root ethanolic extract derived from C. majus was found to be effective against Gram-positive bacteria (S. aureus, Bacillus cereus) (MIC 15.63 and $62.5 \mathrm{mg}$ of dry plant material/mL, respectively), but was inactive against Gram-negative (P. aeruginosa). Also, the concentration of $62.5 \mathrm{mg}$ of dry plant material $/ \mathrm{mL}$ effectively inhibited $C$. candida in these experiments. The aerial parts of $C$. majus used in the study of Kokoška et al. (2002) were inactive against any of the test microbes. The antibacterial activity of sanguinarine (SAG), one of the several alkaloids of $C$. majus, was studied by Zhang et al. (2020) against Providencia rettgeri. All tested plant extracts manifested antimicrobial activity, related to different chemical structures of the alkaloids. SAG demonstrated strong activity against $P$. rettgeri biofilms. SAG not only inhibited biofilm formation but also destroyed the intact and viable biofilm. At 1/16 MIC, SAG inhibited biofilm formation by approximately $68 \%$, whereas at $1 / 4$ MIC, more than $95 \%$ of the biofilm was inhibited, thus an outstanding antibacterial effect of SAG was observed on P. rettgeri (Zhang et al., 2020).

Other in vitro studies have shown that berberine (alkaloid of Papaveraceae family) is effective against Entamoeba histolytica, Giardia lamblia, Trichomonas vaginalis (Kaneda et al., 1991), Helicobacter pylori $\left(\mathrm{MIC}_{50}=12.5 \mu \mathrm{g} / \mathrm{mL}\right.$ ) (Mahady et al., 2003) and Leishmania donovani (Ghosh et al., 1985). Berberine displayed a significant antibacterial and antifungal activity against Staphylococcus aureus and different Candida spp. (MIC $=64 \mu \mathrm{g} / \mathrm{mL}$ for Candida albicans) (Freile et al., 2003). Berberine also inhibits T. vaginalis and its effect is comparable to metronidazole as regards potency (Soffar et al., 2001). In the mechanistic aspect, one study has shown that berberine has potent inhibitory activity against sortase A (SrtA) and sortase B (SrtB). The inhibition of sortase enzymes results 
in a marked reduction in the virulence and infection potential of $S$. aureus, so it may be an important mechanism in the antibacterial activity of berberine (Oh et al., 2006).

\section{Conclusions}

Ethanolic extracts of $C$. majus showed no antimicrobial activity against Enterococcus faecalis strains. However, the results obtained may suggest that the extracts obtained from different parts of $C$. majus need to be subjected to further microbiological and chemical tests for natural antibiotics to evaluate the antibacterial activity and identify secondary metabolites that may be responsible for the above properties. This study lays the foundation for further research to test the feasibility of using C. majus as an alternative method in antibiotic therapy. Knowledge of the phytochemical profile of C. majus will help in explaining the observed activity and designing activity fractionation experiments to isolate the active substances. Identification of precise molecular mechanisms responsible for inhibition of bacterial growth by these extracts requires further research.

\section{Conflicts of interest}

The authors declare no conflict of interest.

\section{Ethical statement}

This article does not contain any studies that would require an ethical statement.

\section{Acknowledgments}

This study was funded by Pomeranian University in Słupsk.

\section{References}

Bauer, A.W., Kirby, W.M., Sherris, J.C., \& Turck, M. (1966). Antibiotic susceptibility testing by a standardized single disk method. American Journal of Clinical Pathology, 45(4), 493-496.

Bonten, M.J., Van Tiel, F.H., Van Der Geest, S., Stobberingh, E.E., \& Gaillard, C.A. (1993). Enterococcus faecalis pneumonia complicating topical antimicrobial prophylaxis. New England Journal of Medicine, 328(3), 209-210. https://doi.org/10.1056/NEJM199301213280311

Brewer, W., Harrison, J., Saito, H.E., \& Fozo, E.M. (2020). Induction of daptomycin tolerance in Enterococcus faecalis by fatty acid combinations. Applied and Environmental Microbiology, 86(20), e01178-20. https://doi.org/10.1128/AEM.01178-20

CLSI (2014). Performance Standards for Antimicrobial Susceptibility Testing. Clinical and Laboratory Standards Institute; Wayne, PA, USA: 2014. CLSI M100-S24.
Colombo, M.L., \& Bosisio, E. (1996). Pharmacological activities of Chelidonium majus L. (Papaveraceae). Pharmacological Research, 33(2), 127-134. https://doi.org/10.1006/phrs.1996.0019

Fisher, K., \& Phillips, C. (2009). The ecology, epidemiology and virulence of Enterococcus. Microbiology (Reading), 155(6), 1749-1757. https://doi.org/10.1099/mic.0.026385-0

Freile, M.L., Giannini, F., Pucci, G., Sturniolo, A., Rodero, L., Pucci, O., Balzareti, V., \& Enriz, R.D. (2003). Antimicrobial activity of aqueous extracts and of berberine isolated from Berberis heterophylla. Fitoterapia, 74(7-8), 702705. https://doi.org/10.1016/s0367-326x(03)00156-4

García-Solache, M., \& Rice, L.B. (2019). The Enterococcus: a Model of Adaptability to Its Environment. Clinical Microbiology Reviews, 32(2), e00058-18. https://doi.org/10.1128/CMR.00058-18

Gerenčer, M., Turecek, P.L., Kistner, O., Mitterer, A., SavidisDacho, H., \& Barrett, N.P. (2006). In vitro and in vivo anti-retroviral activity of the substance purified from the aqueous extract of Chelidonium majus L. Antiviral Research, 72, 153-156. https://doi.org/10.1016/j.antiviral.2006.03.008

Ghosh, A.K., Bhattacharya, F.K., \& Ghosh, D.K. (1985). Leishmani adonovani: Amastigote inhibition and mode of action of berberine. Experimental Parasitology, 60, 404413. https://doi.org/10.1016/0014-4894(85)90047-5

Huycke, M.M., Sahm, D.F., \& Gilmore, M.S. (1998). Multipledrug resistant enterococci: the nature of the problem and an agenda for the future. Emerging Infectious Diseases, 4(2), 239-249. https://doi.org/10.3201/eid0402.980211

Jorgensen, J.H., \& Ferraro, M.J. (2009). Antimicrobial susceptibility testing: a review of general principles and contemporary practices. Clinical Infectious Diseases, 49(11), 1749-1755. https://doi.org/10.1086/647952

Kaneda, Y., Torii, M., Tanaka, T., \& Aikawa, M. (1991). In vitro effects of berberine sulphate on the growth and structure of Entamoeba histolytica, Giardia lamblia and Trichomonas vaginalis. Annals of Tropical Medicine and Parasitology, 85, 417-425. https://doi.org/10.1080/00034983.1991.11812586

Kokoška, L., Polesny, Z., Rada, V., Nepovim, A., \& Vanek, T. (2002). Screening of some Siberian medicinal plants for antimicrobial activity. Journal of Ethnopharmacology, 82, 51-53. https://doi.org/10.1016/S0378-8741(02)00143-5

Lenfeld, J., Kroutil, M., Marsálek, E., Slavík, J., Preininger, V., \& Simánek, V. (1981). Antiinflammatory activity of quaternary benzophenanthridine alkaloids from Chelidonium majus. Planta Med., 43(2), 161-165. https://doi.org/10.1055/s-2007-971493

Macovei, L., \& Zurek, L. (2006). Ecology of antibiotic resistance genes: characterization of enterococci from houseflies collected in food settings. Appl. Environ. Microbiology, 72(6), 4028-4035. https://doi.org/10.1128/AEM.00034-06 
Mahady, G.B., Pendland, S.L., Stoia, A., \& Chadwick, L.R. (2003). In vitro susceptibility of Helicobacter pylori to isoquinoline alkaloids from Sanguinaria canadensis and Hydrastis canadensis. Phytotherapy Research, 17, 217221. https://doi.org/10.1002/ptr.1108

Mcbride, S.M., Fischetti, V.A., Leblanc, D.J., Moellering, R.C., Jr, \& Gilmore, M.S. (2007). Genetic diversity among Enterococcus faecalis. PloS One, 2(7), e582. https://doi.org/10.1371/journal.pone.0000582

Murray, B.E. (1990). The life and times of the Enterococcus. Clinical Microbiology Reviews, 3(1), 46-65. https://doi.org/10.1128/CMR.3.1.46

Oh, K.B., Oh, M.N., Kim, J.G., Shin, D.S., \& Shin, J. (2006). Inhibition of sortase-mediated Staphylococcus aureus adhesion tofibronectin via fibronectin-binding protein by sortase inhibitors. Applied Microbiology and Biotechnology, 70, 102-106. https://doi.org/10.1007/s00253-005-0040-8

Okoth, D.A., Chenia, H.Y., \& Koorbanally, N.A. (2013). Antibacterial and antioxidant activities of flavonoids from Lannea alata (Engl.) Engl. (Anacardiaceae). Phytochemistry Letters, 6, 476-481.

https://doi.org/10.1016/j.phytol.2013.06.003

Pantano, F., Mannocchi, G., Marinelli, E., Gentili, S., Graziano, S., Busardò, F.P., \& Di Luca, N.M. (2017). Hepatotoxicity induced by greater celandine (Chelidonium majus L.): a review of the literature. European Review for Medical and Pharmacological Sciences, 21(1), 46-52.

Shepard, B.D., \& Gilmore, M.S. (2002). Antibiotic-resistant enterococci: the mechanisms and dynamics of drug introduction and resistance. Microbes and Infection, $4(2), 215-224$. https://doi.org/10.1016/s1286-4579(01)01530-1

Soffar, S.A., Metwali, D.M., Abdel-Aziz, S.S., El-Wakil, H.S., \& Saad, G.A. (2001). Evaluation of the effect of a plant alkaloid (berberine derived from Berberis aristata) on Trichomonas vaginalis in vitro. Journal of the Egyptian Society of Parasitology, 31, 893-904.

Stefanowski N., Tkachenko, H., \& Kurhaluk, N. (2021b). Evaluation of the antibacterial activity of ethanolic extracts obtained from roots and stalks of Chelidonium majus L. against Escherichia coli strains. Agrobiodiversity for Improving Nutrition, Health, and Life Quality, 5(1), 126-132. https://doi.org/10.15414/ainhlq.2021.0013
Stefanowski, N., Tkachenko, H., \& Kurhaluk, N. (2021a). Preliminarily evaluation of the antimicrobial activity of extracts derived from leaves and roots of Chelidonium majus L. sampled in rural and urban agglomerations of northern Poland. Youth and Progress of Biology: Abstracts of XVII International Scientific Conference for Students and Ph.D. Students (Lviv, April 19-21, 2021). Lviv: LLC Romus-Poligraf. ISBN 978-617-7809-39-4.

Stefanowski, N., Tkachenko, H., \& Kurhaluk, N. (2021c). Antimicrobial activity of Chelidonium majus L. extracts against Escherichia coli strain. Scientific progress in animal husbandry and poultry: Proceedings of the $\mathrm{XV}$ All-Ukrainian scientific-practical conference of young scientists, Kharkiv, August 26-27, 2021, Institute of Animal Husbandry NAAS. Kharkiv.

Zar, J.H. 1999. Biostatistical Analysis. $4^{\text {th }}$ ed., Prentice-Hall Inc., Englewood Cliffs, New Jersey.

Zhang, Q., Lyu, Y., Huang, J., Zhang, X., Yu, N., Wen, Z., \& Chen, S. (2020). Antibacterial activity and mechanism of sanguinarine against Providencia rettgeri in vitro. PeerJ., 8, e9543. https://doi.org/10.7717/peerj.9543

Zielińska, S., Jezierska-Domaradzka, A., Wójciak-Kosior, M., Sowa, I., Junka, A., \& Matkowski, A.M. (2018). Greater celandine's Ups and Downs-21 centuries of medicinal uses of Chelidonium majus from the viewpoint of today's pharmacology. Frontiers in Pharmacology, 9, 299. https://doi.org/10.3389/fphar.2018.00299

Zuo, G.Y., Meng, F.Y., Hao, X.Y., Zhang, Y.L., Wang, G.C., \& Xu, G.L. (2008). Antibacterial alkaloids from Chelidonium majus Linn (Papaveraceae) against clinical isolates of methicillin-resistant Staphylococcus aureus. Journal of Pharmacy and Pharmaceutical Sciences, 11(4), 90-94. https://doi.org/10.18433/i3d30q 